\title{
Contradicciones de la trama narrativa en cuentos de Roberto Bolaño
}

\author{
Contradictions of the plot in Roberto Bolaño's short stories
}

\begin{abstract}
Luis Alberto Velarde ${ }^{1}$
Resumen

En este artículo se examinan las estrategias narrativas utilizadas por Bolaño en aquellos cuentos marcados por un debilitamiento de la trama. La virtualidad de la acción narrativa, los anticierres, el lirismo, las conjeturas, entre otros, son considerados como sustitutos de los enlaces narrativos que permiten la unidad y completitud del relato. Pese a la apertura, el carácter episódico de las acciones, la aparente falta de selecciones de éstas y la espacialidad inherente al lirismo y las conjeturas, los cuentos se encuentran provistos de la unidad característica de la trama. Se sostiene que precisamente es en las características de la trama y sus procedimientos donde se evidencia la propuesta estética de Bolaño y el punto de partida de la interpretación de los textos, sus significados en tanto objetos socialmente simbólicos. En este sentido se interpretan las tensiones que se observan en la configuración de la trama en relación con la inteligibilidad de la acción humana, evaluando el llamado pesimismo de la narrativa de Bolaño en el marco de aquello que según Grínor Rojo corresponde al ciclo literario al que pertenece.
\end{abstract}

Palabras clave: trama, tiempo narrativo, estética, Bolaño, relato.

\begin{abstract}
This article examines the narrative strategies used by Bolaño in those stories marked by an undermining of the plot. The virtuality of the narrative action, the anti-closures, the lyricism and the conjectures are considered as substitutes for the narrative nexus that allow the unity and completeness of the story. Despite the openness, the episodic nature of the actions, the apparent lack of selections from these and the spatiality inherent in lyricism and guesswork, the stories have the characteristic unity of the plot. It is precisely in the characteristics of the plot and the procedures used that Bolaño's aesthetic proposal is evident and the starting point of the interpretation of its meaning as a socially symbolic object. In this sense, the tensions observed in the configuration of the plot in relation to the intelligibility of human action are interpreted, evaluating the pessimism of Bolaño's narrative within the framework of the literary cycle to which it belongs and the descriptions of its production made by critics like Grinor Rojo.
\end{abstract}

Keywords: plot, narrative time, aesthetics, Bolaño, short story.

\section{Presentación}

¿Cuál es la forma del tiempo en los cuentos de Bolaño? ¿Cómo se configura la trama en ellos? Estas preguntas de entrada pueden parecer forzadas y exteriores, sin embargo, la perplejidad que acusan las lecturas de los cuentos de Roberto Bolaño tiene que ver con las estrategias narrativas empleadas en ellos a fin de conferir una cierta unidad a las acciones relatadas. Se ha dicho, por ejemplo, que mantienen al lector "en vilo" frente a tramas abiertas y errantes con "un orden donde los hechos se suceden imprevisibles y (sic) interminables" (Andrews, 2003, p. 33). Este problema

\footnotetext{
${ }^{1}$ Investigador independiente. Correo electrónico: luis.velarde.f@gmail.com https://orcid.org/0000-0003-0095-7833.
} 
encierra las conocidas tensiones entre convencionalidad y autenticidad, dispersión y enlace narrativo, espacialidad y temporalidad, chronos y kairós. Este artículo se dedica a este tema, precisando algunos aspectos de la narrativa de Bolaño que determinan la particularidad de las tramas en sus cuentos.

Es preciso indicar, no obstante, que la trama en la narrativa moderna se ha desarrollado según una orientación marcada por su debilitamiento. En su prólogo de 1940 a La invención de Morel, Borges (1999), por ejemplo, constata el desdén de la institución literaria contemporánea hacia las peripecias y su conformidad respecto a la novela sin argumento, pero valora aquellas producciones literarias que sí habían asumido el desafío de construir una trama, dejando entrever una pugna entre dos visiones de la narrativa en torno a lo que llamaba "imaginación razonada" (1999, p. 14). Otro tanto añade Eco al señalar que la carencia de trama de la obra abierta es sólo "una de las manifestaciones" (1965, p. 176) de la poética contemporánea. Y es que, sea o no el caso de la desaparición de la trama del mapa literario moderno o incluso posmoderno, se debe convenir en que esta categoría narrativa ha visto por lo menos modificaciones, como aquellas que esquematiza Ricoeur, identificando el paso de tramas de acciones, a tramas del carácter y de ahí a tramas de pensamiento (2017, p. 393). Del mismo modo, cabe considerar las coerciones que ejerce el propio género sobre las intenciones de los escritores, como constata Kermode (2000) al analizar La náusea de Sartre, revelando la dificultad de eludir la figura del héroe.

En el caso de Bolaño encontramos aquella tensión descrita por Borges: la convivencia de las tradiciones realista y vanguardista (Corral, 2011, p. 79). Por ello no resulta injustificado examinar el papel que ejerce la construcción de la trama en la narrativa del escritor chileno, cómo conviven esas tradiciones y de qué manera afectan las orientaciones de sentido de los cuentos. Esto considerando que la narrativa de Bolaño se ha ubicado en un ciclo literario marcado por el sentimiento de derrota, recogido en su obra en la forma de "una pérdida acerca de la cual se presume una cierta responsabilidad ajena o propia" (Rojo, 2016, p. 51). Las novelas tanto de Bolaño, como las de Diamela Eltit, Carlos Franz, entre otros escritores chilenos, se caracterizan estéticamente, según Rojo, por un romanticismo de la decepción, en una doble dimensión cultural y política, en la que "asoma la sospecha de que aquello que se perdió no merecía la confianza que ellos mismos le otorgaron" (2016, p. 52). .

Por otra parte, la misma producción narrativa de Bolaño, sea cuento o novela, se orienta en dos direcciones distintas. Se encuentran, por un lado, relatos que evidencian la unidad de su trama, en torno a la cual las peripecias son comprensibles; mientras que, por otro, se aprecian historias aparentemente indescifrables debido a que la trama convencional se encuentra debilitada hasta el punto de constituir poco más que accidentes agrupados por un cierto lirismo del narrador. El mismo autor señalaba sobre Nocturno de Chile que "está construida en una sucesión de cuadros en donde casi no hay punto de ilación o bien los puntos de unión entre un cuadro y otro son puramente experimentales" (cit. en Rojo, 2016, p. 170). Dos cosas se desprenden de la descripción que Bolaño hace aquí: existe la exploración consciente del tema de la trama por parte del escritor, así como también su valor estructural interno. En esta medida, la presente investigación respeta la naturaleza de la propuesta narrativa misma sin necesidad de imponer el elemento teórico sólo formal y exteriormente. En suma, se concibe el problema de la trama como clave de inteligibilidad.

¿Qué hacer, sin embargo, con la doble dirección de la narrativa mencionada? Siguiendo la vieja aserción de Yuri Tinianov (1970) de acuerdo con la cual la sustracción de un elemento integrante del texto literario permite al investigador valorar la función y la importancia de otros aspectos, este artículo se concentra en los casos de anomalía, por así decirlo, es decir, se enfoca en los cuentos cuya trama se nos presenta debilitada. Se considera, además, que la descripción y el

\footnotetext{
${ }^{2}$ La tesis contraria, es decir, la formalista consiste en ver en la narrativa del autor la motivación por revelar sus "mecanismos de funcionamiento" (Ríos, 2015, p. 14), algo que por cierto se puede fácilmente descubrir en vasta parte de la literatura moderna, por razones estéticas muy estudiadas.
} 
análisis de la estructura o "composición técnica" adquiere sentido en virtud de la "arquitectura estética" (Bajtín 1989), esto es, conforme a su valor simbólico, en tanto "estructura determinada de contradicciones todavía puramente formales" (Jameson, 1989, p. 63), asumiendo que las técnicas y procedimientos no se agotan en sí mismos sino que se vinculan a una proyección de sentido. Con todo, la exposición se realiza a partir de la propuesta de características y definiciones conceptuales que pueden ser observadas en diversos cuentos de Bolaño y que se justifican en la medida en que describe la organización de la trama.

\section{Entre chronos y kairós: sentido y necesidad}

La interpretación, según la cual los relatos de Bolaño muestran su propia dificultad representativa, en la que "resulta imposible contar el mundo, y solamente es capaz de contarse a sí mismo lo que está tratando de representar" (Ríos, 2015, p. 15), manifiesta desde ya que la narrativa del autor chileno se encuentra en abierta confrontación con la clásica estructura argumental. Los elementos básicos de sucesión y transformación (Todorov, 2012, p. 88), obtuvieron su primera concepción en las descripciones realizadas por Aristóteles en su Poética, donde quedaba de manifiesto que la unidad y la completitud son componentes categoriales de la trama. El ciclo completo de inicio, medio y fin propio del relato se ve amenazado en los cuentos de Bolaño, algo que, por lo demás, resulta evidente al cabo de la lectura de cuentos tales como "Últimos atardeceres en la tierra" (2001) o "Jim" (2009). Si nos referimos sólo a las cualidades definidas por Bremond (1974) en relación con los segmentos necesarios de la acción narrativa, esto es, "que estén dadas las modalidades de su origen, la de su desarrollo, las de su culminación" y que se trate de "un proceso orientado, de una virtualidad que se actualiza y tiende hacia un cierto término" (p. 90), advertimos que la trama en los cuentos considerados en este artículo se mantienen en la pura virtualidad, sin dar paso al acto en acciones que, además, en muchos casos carecen de origen delimitado, o bien se relatan a partir de la incertidumbre, tal como se pone de manifiesto en las expresiones "como si" y "puede que" en cuentos como "Vida de Anne Moore" (Bolaño, 2018). Adrews (2008, p. 53), por ejemplo, observa que en "Últimos atardeceres en la tierra" las acciones tienen un carácter meramente episódico. En efecto, al principio de este cuento, cuando se presenta el viaje que realizan B y el padre de B, el narrador parece limitarse a presentar acciones inconexas según su mera sucesión, es decir, como una cronología que se sustrae a la fuerza organizadora del principio de transformación.

En una segunda parte, luego de que B y el padre de B se hospedaran y pasearan por Acapulco, "se acaba el paréntesis", entonces el narrador nos asegura que comienza "un desastre que por encima de todo aleja a B de su padre, el precio que tienen que pagar por existir" (Bolaño, 2001, p. 56). Los personajes salen con un ex-clavadista que acaban de conocer a cenar y entretenerse en un bar, luego a un local de suburbios en donde beben y juegan cartas con desconocidos. El cuento finaliza cuando el narrador dice "Comienzan a pelear" (Bolaño, 2001, p. 63), sin informar mayores detalles del resultado de esta pelea. No está de más señalar que el "desastre", unido a otras evocaciones igualmente oscuras, se define poco más que por su misterio. Nos informamos que la pelea con que termina el cuento implica un cambio pero no tenemos acceso a su inteligibilidad, sino que sólo podemos percibir, en un nivel enigmático, que dicho enfrentamiento debería revelar una verdad oculta, aunque no la naturaleza de la misma. Así pues, las acciones se organizan como aperturas de posibilidades de procesos sugeridos o indeterminados. $\mathrm{Si}$, frente al chronos, Kermode define kairos como aquella temporalidad en que "la mera sucesión, que sentimos como la principal característica en el común transcurrir del tiempo, es eliminada al establecerse una relación significativa entre el momento y un principio y un fin remotos" (2000, p. 55), ${ }^{3}$ entonces podemos decir que el carácter de kairos en este cuento nos llega por la sugestión

\footnotetext{
${ }^{3}$ Cursivas del autor.
} 
de que los eventos se enmarcan en un cambio apocalíptico, pero que permanece oculto o silenciado. De esta manera, advertimos una tensión entre, de una parte, los sucesos registrados como mero ser ahí, o sea, sin la penetración del concepto y, de otra parte, la insoportable renuncia al sentido, aunque sólo sea bajo una forma oscura y enigmática. En cuanto ser ahí, el mundo y las acciones son ajenos a los personajes y al narrador; y en cuanto ajenos, misteriosos. Sin embargo, adquieren su oscuridad en el marco de un cierto orden dado por el "desastre" por venir; según Bolaño (2004), un más allá del campo narrativo del caos legible.

Caso semejante es "Vagabundo en Francia y Bélgica" (2011), también incluido en Putas asesinas. Aquí en vez de "desastre" hallamos la "sorpresa" y una "señal terrible" (Bolaño, 2001, p. 89), definidas también como el advenimiento de un acontecimiento que nunca se explicita, como si el lector fuera llamado a encontrar rastros que aclaren este anuncio. Junto al carácter virtual de la trama, unificada por este enigma, "Vagabundo en Francia y Bélgica" comparte con "Últimos atardecer sobre la tierra" el motivo narrativo del desconocimiento, el que es completado mediante conjeturas, así como también por un lirismo que envuelve a los objetos con un halo misterioso; por ejemplo, cuando los personajes B y M visitan un museo se lee la siguiente descripción: "unas máquinas que tal vez no son máquinas sino esculturas incomprensibles, el desfile de la humanidad doliente y riente hacia la nada" (Bolaño, 2001, p.90). Sin duda, estas estrategias surgen del propio problema de la trama en Bolaño: en ausencia del circuito completo de la acción narrativa, los enlaces y el sentido de éstos descansan en el lirismo y el anuncio, esto según lo que Todorov llama transformación por potencia evocadora (2012, p. 96). Sin embargo, lo importante aquí es el estatuto que tienen estos procedimientos, si pensamos la narrativa como "acto socialmente simbólico" (Jameson, 1989), es decir, de acuerdo al modo en que mediante las configuraciones del mundo narrativo se expresan sentidos históricos y sociales. Aquí cobra, entonces, importancia la tensión entre chronos y kairós, algo que el cuento "Gómez Palacio" (2001) nos revela por medio de una reflexión del protagonista, quien consigue un trabajo para dirigir un taller de literatura, pero del que no está seguro ni comprende el significado de su propio destino allí:

Todo aquello no tenía sentido, pensaba, pero en el fondo sabía que tenía sentido y ese sentido era el que me desgarraba, para utilizar una expresión un tanto exagerada que yo, sin embargo, no consideraba exagerada. Tal vez confundía entonces sentido con necesidad. Tal vez solo estaba nervioso. (Bolaño, p. 29)

La necesidad de sucesión aparenta un sentido dado por su propia existencia y, sin embargo, cabe sospechar que este no sea otra cosa que resignación frente a la exterioridad del tiempo. En "Gómez Palacio", el ambiente en el que se hunden las acciones y que les confiere unidad descansa en la pérdida de sentido y la emergencia de intuiciones escatológicas, presididas, a su vez, por un pesimismo que en este caso se revela sólo al protagonista en su calidad de extranjero. El personaje contempla distante su entorno y le parece condenado. Mientras dicta el taller de literatura observa a uno de los integrantes del grupo, lo imagina de niño por las calles de Gómez Palacio "bajo un cielo que se asemejaba a un alud de piedras", luego ve al resto del grupo y piensa: "imposible que sobrevivan” (Bolaño, 2001, p. 31). Pero, ¿a qué? Se superponen aquí dos sentidos: uno sobre el contexto inmediato, a saber, la labor del poeta, y otro sobre un más allá de las cosas directamente enfrentadas. Como ha sido señalado por Piglia (2017, p. 103), el cuento relata dos historias, ${ }^{4}$ pero en Bolaño "la historia secreta no aflora" (Aguilar, 2015, p. 127), debido a que "los puntos suspensivos", de los que habla Aguilar, se logran mediante la falta de selección en las acciones, la aparente limitación del narrador a la mera sucesión, lo que obliga la atención por igual de cada

\footnotetext{
${ }^{4}$ Piglia (2017) asegura en sus tesis que el cuento tiene un carácter doble, es decir, propone dos historias, una de las cuales es evidente, mientras la otra queda cifrada y se desarrolla elípticamente. El efecto del cuento descansaría en la sorpresa provocada en el final cuando la segunda historia sale a superficie.
} 
elemento bajo la sugestión de trascendencia. Algo que el propio relato se encarga de motivar, constatando una ausencia, la emergencia de algo por venir o, incluso, algo que ya ha ocurrido inadvertidamente: el desastre, la sorpresa, el estallido, entre otros.

\section{Apertura y anticierre}

Se ha visto que Bolaño en estos cuentos oblitera la estructura clásica de la trama y, sin embargo, se resiste a la pura arbitrariedad y dispersión de los acontecimientos a través de un elemento que puja por romper el accidente, proyectando sobre él una sombra que le confiere una orientación sugerente: el anuncio a cada tanto de algo por venir. Pero en la medida en que se desdibujan los contornos clásicos de la trama, el principio de completitud se ve igualmente afectado. Aunque la modernidad trajo consigo el carácter abierto de la obra junto a su deriva de "indeterminación y discontinuidad" (Eco, 1965), se debe admitir que en una narración, una acción cualquiera no implica un nuevo comienzo, esto es, que reconocemos en ella su unidad y conclusividad. En esta percepción entran en juego aspectos culturales que pertenecen a "la relación cognoscitiva en el curso de la cual se realizan aperturas provocadas y dirigidas por los estímulos organizados de acuerdo con una intención estética" (Eco, 1965, p. 79); en otras palabras, convienen a un momento de la totalidad del ser social, lo que incorpora en sí la expectativa del receptor (Kermode, 200, p. 29).

El final mismo, por otro lado, ha tenido una evolución en la literatura y la sociedad, surgiendo nuevas nociones de completitud. Jameson dice que "las cosas incompletas -el cuento de Chejov, el fragmento, la novela sin trama-, habiendo sido promovidas a géneros por derecho propio, ya no son consideradas abiertas, sino que presentan una nueva clase de cierre" (2013, pp. 584, 585). En definitiva, se trata de entender los llamados "anticierres" (Ricoeur, 1997, p. 406 y ss.) como otras tantas estrategias de clausura de un texto.

Alrespecto, resulta ejemplar la discrepancia entre Solotorevsky y Andrews sobre cómo interpretar el final de "Últimos atardeceres en la tierra", pues aquí se revela la estrategia utilizada por el autor. Mientras Solotorevsky sostiene que, a partir de distintos anuncios dispersos en el relato, cabe interpretar que los personajes B y padre de B mueren, Andrews tiene la idea de que los personajes viven y comienzan una nueva historia, también fundando su interpretación en anuncios del propio relato. Solotorevsky afirma con razón que este cuento "permite así interpretaciones opuestas" (2009, p. 4). Sin duda, la desavenencia descansa, en primer lugar, en el valor otorgado a lo que hemos llamado anuncios, la elección de éstos y a la sugestión que promueve la aparente falta de selección. Pero, en segundo lugar, esto depende del doble carácter que tiene la temporalidad en los cuentos de Bolaño. La posibilidad de hacer de la experiencia cotidiana, contingencial y singular, un relato que debe percibirse en un plano universal, está condicionada por la universalidad de la experiencia privada, su socialización, así como también por la sugerencia de que este propio mundo privado se excede en cuanto a su dación. Cuando Solotorevsky dice que Andrews interpreta los anuncios tal si B "está pensando en el día siguiente" (2009, p. 4), mientras ella admite la posibilidad de narrar desde la muerte, se expresan dos niveles del tiempo: uno individual y otro trascendental.

En un cuento que tiene un carácter distinto, acaso sólo individual, como "Clara" (2018), la estrategia del anuncio de la muerte permite un cierre pero, a diferencia de aquellas tramas que terminan por dar cumplimiento o no a una meta luego de la complicación, se vulnera la expectativa motivada en el mismo relato. La muerte de Clara, debido al cáncer, opera como una sombra sobre las acciones y sobre aquello que Solotorevsky (2009) denomina isotopías, pero la muerte misma queda delimitada como un anuncio, una ausencia que determina el carácter conclusivo de la trama, bien que no pase de la virtualidad al acto. Como en otros cuentos la segunda historia no emerge: anuncios tales como "pero a la larga me iba a costar caro" (Bolaño, 2018, p. 156) o sugerencias de sentido como "lo único que quería decir no se lo podía decir" (p. 163), carecen de contornos claros; 
antes bien, ejercen por sí mismos una función narrativa por cuanto encierran las acciones en un ámbito enigmático. Esto induce a pensar que los anuncios no son dato suficiente para las interpretaciones que hacen Solotorevsky y Andrews de "Últimos atardeceres en la tierra", puesto que tienen una función en la trama y la configuración temporal, más que como información certera sobre el destino de los personajes fijados en las narraciones. Esta temporalidad radica en el aveum (Kermode, p. 80) que integra el inicio, el medio y el final a través de una concordancia, aunque débil y en el campo de la incertidumbre. Desde luego, esta estrategia confiere calidad argumental al final fáctico del cuento, lo cual permite percibirlo como final "culminante" (Solotorevsky p. 3). Los anticierres obtienen su peso en el marco de la dispersión y aparente falta de selección de los objetos, acciones y personajes, por cuanto plantean una cierta unificación de lo discordante o heterogéneo.

Esta estrategia narrativa en "Últimos atardeceres en la tierra" expresa la integración de destinos individuales y del mundo mismo, una unidad de tiempos. El personaje adquiere la misma naturaleza que el mundo al que pertenece: la ruina es de ambos. En el caso de "Clara" tiene que ver con la unión de los tiempos del personaje de Clara y del narrador, quien deja entrever que el destino de aquella lo implica cuando dice "una Clara que ya más podría conocer, acariciar, ayudar. Una Clara que jamás me podría salvar” (Bolaño, 2018, p. 63). Aquí la sombra de la muerte de Clara tiñe tanto la historia del personaje como la del narrador, aunque los enlaces de ambos sólo sean sugeridos.

La peculiaridad de Bolaño en estos anticierres consiste en superar la integración mítica de las temporalidades, proponiendo una síntesis basada en la diferencia y el caos existenciales, es decir, asentando el mundo narrativo en las crisis, queden éstas limitadas aparentemente en el plano individual o surjan en ellas connotaciones ontológicas y trascendentes.

\section{Enlaces evocativos: lirismo, conjeturas y sueños}

La heteróclita trama de estos cuentos se persigue a través de la inminencia de un cambio que, sin embargo, queda fuera del mundo narrado. En medio de la simple sucesión, una crisis se avizora como unidad de extremos temporales, extrayendo "de la materia primera de la situación las formas de un futuro" (Kermode,200, p. 87). Por otro lado, además del sentido de la unidad, las acciones se encadenan según una selección que busca desligarse de sí como principio de selección. Lo que rige esta desorganización aparente es la síntesis evocativa. Admitiendo la secuencialidad del tiempo, pero sustrayendo la transformación en acto, aparecen la espacialidad del lirismo, los sueños y conjeturas con la función de enlazar las acciones en virtud de la evocación de sentido. La trama de Bolaño, conforme a la tendencia moderna, evita los enlaces narrativos causales, acercándose más bien a la dispersión existencialista. Pero, como también ha mostrado Kermode, cabe pensar en coerciones propias del género que pugnan por el surgimiento de estrategias que permitan a la ficción seguir siéndolo pese a sus cambios.

El vínculo entre la narrativa de Bolaño y la poesía ya ha sido señalado en distintas investigaciones (Corral, 2011; Ríos, 2015; Ayala, 2008). Pero aquí se quiere destacar el lirismo en tanto procedimiento auxiliar que permite el enlace de lo heterogéneo, de acciones que, como hemos visto, no se hallan encadenadas según los motivos propios de la narración descritos, por ejemplo, por Bremond. Es la función narrativa que tendrían las llamadas isotopías: analépsis, metadiégesis, conjeturas, entre otras. Desde luego, en un plano puramente genérico, este procedimiento también concierne a la tendencia de la narrativa a incorporar en su textualidad discursos ajenos, en una lucha contra la convencionalidad entendida como inauténtica (Ricoeur, 2017, p. 384; Ranciere, 2011, pp. 25, 31, 39), ${ }^{5}$ o bien enajenante. No se debe perder de vista, por tanto, que el estatuto de estos procedimientos estriba en la búsqueda de sentido, en oposición a las

${ }^{5}$ Sobre el asentamiento de la prosa en relación con el verso, ver Moretti (2015), pp. 181-187 passim. 
inercias que enajenan nuestra percepción del mundo. El mismo escritor había señalado su afán por captar nuevos contenidos de la experiencia mediante la exploración de su escritura. ${ }^{6}$

El lirismo tiene una función sintética, acercando elementos heterogéneos a fin de explotar las posibilidades evocativas, así las comparaciones, imágenes y las metáforas abundan, ya que por sí mismas operan según este carácter sintético. Sin embargo, el lirismo aquí es más que una revelación de las verdades de una realidad prosaica, como si esta no fuese por sí y se limitara a expresar algo que le es ajeno; antes bien, su valor reside en su interacción con la prosa del mundo; algo que advierte Andrews cuando dice que "el narrador rompe el vuelo lírico con unas frases secas y pedestres" (2015, p.36). Al respecto, resultan decidoras las palabras que Bolaño (2009) pone en boca de Jim, en el cuento homónimo, quien, a contrapelo de una estetización voluntarista del mundo, dice: "soy poeta y busco lo extraordinario para decirlo con palabras comunes y corrientes" (p. 11). En "Jim" se puede observar el uso de las conjeturas cuando el narrador se dedica a relatarnos una acción imaginada por él: "La imaginé en un apartamento de San Francisco o en una casa de Los Ángeles..." (p. 12), o también al describir y tratar de hacer inteligible una acción: "como si esperara algo más del tragafuegos... como si en el rostro tiznado hubiera descubierto la cara de un antiguo amigo o de alguien que había matado" (pp. 12,13). Justamente en este contexto el principio evocativo aparece con mayor evidencia:

un cuello que evocaba, de alguna manera, un linchamiento en el campo, un campo en blanco y negro, sin anuncios ni luces de estaciones de gasolina, un campo tal como es o como debería ser el campo: baldíos sin solución de continuidad, habitaciones de ladrillo o oblindadas de donde hemos escapado y que esperan nuestro regreso. (Bolaño, 2009, p.12).

Sin estos insertos líricos y conjeturales las acciones carecen del tono que permite su singularidad, a la que apela el relato a propósito de la unidad y completitud de la trama. En otras palabras, la profundidad y sugerencia de trascendencia de un cuento como "Jim" descansa en las posibilidades evocativas del lirismo y la conjetura. De tal manera, tienen participación en la trama como enlaces auxiliares, a diferencia del significado que pueden obtener las acciones a través del encadenamiento causal y conforme a la estructura clásica de la trama. El significado que adquieren las acciones en un cuento como "Jim" provienen de la exploración de nuevas relaciones de los componentes de la realidad y sus discursos, bajo la sugestión de una unidad entre elementos distintos más allá tanto de la mera sucesión como de la causalidad.

Por ello el lirismo, la conjetura o los sueños de B en "Vagabundo en Francia y Bélgica" y de otros tantos personajes, no simplemente revelan una verdad por sí y con independencia de la prosa del mundo, sino más bien sugieren conexiones que puedan abrir la posibilidad de transformaciones más allá del desierto de lo real y la dispersión de sus elementos. En estos cuentos notamos una narrativa que guarda estrecha relación con las aperturas del mundo y de la captación de éstas, tanto más cuanto que la ficción, como dice Kermode, se basa precisamente en un acuerdo desobligado que supera la veneración mítica. ${ }^{7} \mathrm{Si}$ el escritor debe sacar del propio género las posibilidades de verdad o sentido, la búsqueda de autenticidad preside su lucha contra los medios anquilosados y alienados de la inercia que yacen en el mismo género. Aquí es donde el papel de estos enlaces se torna evidente, así como también su orientación hacia la realidad, considerando que la pugna con la convencionalidad podría derivar en un mero alejamiento de la vida y la realidad comunes. ${ }^{8}$

\footnotetext{
${ }^{6}$ Véase la entrevista concedida a "La belleza de pensar", en 1999, en el marco de la Feria internacional del libro de Santiago.

${ }^{7}$ Ver también Lotman, 2013, pp. 261-265.

${ }^{8}$ Este es el juicio de Ricoeur sobre el devenir de la novela, ver Ricoerur, 2017, pp. 391-392.
} 


\section{Contradicciones en la narrativa de Bolaño}

La trama por sí misma es un "modelo" (Lotman, 2011, 269) de la acción humana, su inteligibilidad, su destino y las posibilidades de obrar con libertad. La trama involucra en su estructura aspectos que modelan el sentido de la práctica humana mediante el enlace narrativo de lo heterogéneo (Ricoeur, 2017, 380). En su "Narrar o describir", Lukács (1966) señalaba que el enlace narrativo por medio del cual una obra del género épico alcanza su esencia estética se define por la articulación de las cosas, las relaciones interindividuales, los acontecimientos del mundo exterior, las fuerzas naturales, las instituciones sociales, las acciones en función del destino humano concreto. Pero cuando este enlace de la diversidad de los elementos mencionados se encuentra desdibujado, cuando el sentido estético que permite dirimir sobre este orden ya no es evidente, la narración puede derivar en la aplicación de sustitutos narrativos. Aparecen, entonces, la descripción naturalista, el simbolismo, el formalismo, el psicologismo y el sociologismo; las cosas se humanizan cosificando a los humanos, las descripciones vuelven estáticos e independientes, como animados por sí mismos, a los objetos. En suma, el arte épico pierde su esencia consistente en "la distribución justa de los pesos, en la justa acentuación de lo esencial", apareciendo tanto el individuo como su práctica social bajo la forma de un "producto artificioso rebuscado, como resultado de un virtuosismo... como algo inventado" (Lukács, 1966, pp. 186-187).

Pues bien, parece que la narrativa de Bolaño en los cuentos cuya trama se ha debilitado, está determinada por el pesimismo y la desarticulación, sin embargo, cabe dudar de la extensión de un juicio tal. No sólo en relación con el corpus, o sea, con la muestra considerada para fundamentar el juicio, sino en virtud de las contradicciones en la narrativa de Bolaño. Al contrario de lo que dice Lukács sobre las consecuencias de rebajar el estatuto estético de la narración mediante sustituciones descriptivas, a saber, que torna "todas las cuestiones ideológicas en abstractas" (Lukács, 1966, p. 203), los cuentos de Bolaño se basan en la profundización de la realidad concreta. Sus estrategias de enlace narrativo se integran al devenir de la trama y no se dedican a estetizar la prosa del mundo, así como tampoco reclaman una verdad unilateral a partir de romantizar la marginación y la anomia. No hacen de la falta de sentido un sentido exultante por sí mismo.

En Bolaño el relato de una experiencia atada a la inmediatez de las cosas, su puro aparecer accidental o chronos, debería participar de un énfasis en la pérdida de unidad, de una profunda brecha con la universalidad y, sin embargo, como se ha visto, ésta acecha bajo la forma de una inminencia, kairós, que reúne la contingencia discordante. ${ }^{9}$ Aquí no se rechaza el caos ni el accidente, sino más bien se lo admite en su estatuto a condición de integrar un mundo más amplio cuyo borde no se deja observar. La incertidumbre permea las cosas y las personas, pero no logra enajenar completamente el mundo y hacer del sujeto algo extraño a sí mismo y a su entorno. Esto debido a dos razones: las incertidumbres del sujeto son asimismo las del mundo, entretejiendo sus destinos mediante la sugestión de trascendencia, bien que se ofrezcan con un halo de fatalidad; además, tanto las personas como los objetos quedan integrados igualmente a través de un cambio por venir o que ya ha sucedido, es decir, la transformación propia de la trama, aunque queda fuera de las acciones relatadas, continúa ejerciendo un papel en ellas. En otras palabras, más allá del pesimismo, en estos cuentos de Bolaño lo singular no logra ser tal sino a partir de un marco contra el cual referirse, la universalidad que se revela en la figura de una catástrofe, un desastre, una sorpresa, etc.

\footnotetext{
${ }^{9}$ Cabe excogitar que la inclusión de lo accidental en un marco universal embona de mejor manera con la percepción estética. Ver Hegel (2011), Lecciones sobre la estética.
} 
Pero si la trama de los cuentos de Bolaño se mantiene en la etapa de la virtualidad indicada por Bremond, proyectan, por otro lado, una apertura marcada por anuncios escatológicos. ${ }^{10}$ Bajtín decía que la "aparición de contradicciones sociales empuja el tiempo hacia el futuro. Cuanto más profundamente se manifiesten estas contradicciones, más desarrolladas estarán; más importante y amplia podrá ser la plenitud del tiempo en las representaciones del artista” (1989, p. 299). En Bolaño se encuentra esta tensión manifiesta en los finales con anticierres. Un futuro histórico en el que se confiaba se ha difuminado y los despojos humanos de proyectos gigantescos que no alcanzaron a integrar cada vida particular o que luego de "ser usadas sin descanso ni piedad" (Bolaño, 2001, p. 105), han sido desechados sin contemplaciones y, sin embargo, esto no ha implicado que el mundo se haya cerrado de una vez por todas. Antes al contrario, sin triunfalismo y certezas, incluso con sospechas y desesperanza, el mundo continúa abierto. El cambio sigue siendo una perspectiva aunque existan reservas sobre su naturaleza. De esta manera, se observa en Bolaño la estrategia del anuncio cuya equivocidad sugiere la conclusividad de la trama, reuniendo las acciones, a la vez que los planos de interpretación de los mismos, acotados o trascendentes, individuales u ontológicos. Resulta importante observar que el plano clasificatorio o sin argumento contra el cual debe ocurrir el cambio y en cuya transgresión tiene lugar el acontecimiento (Lotman, 2011, pp. 283-292), en Bolaño abarca la lógica del mundo mismo junto a la percepción cotidiana de éste, lo que conlleva una transformación mucho más fuerte que la mera sucesión episódica que nos presenta en primera instancia.

En suma, las mismas formas narrativas desplegadas en los cuentos se encuentran tensionadas por los principios de concordancia y discordancia. La aparente falta de selección de las acciones queda, por otro lado, superada por la evocación de sentidos, en virtud de los cuales se establecen conexiones. Los anticierres sólo surgen a partir de las expectativas promovidas por los anuncios, volviendo evidentes la conclusividad y la no conclusividad del relato. El carácter sucesivo del tiempo se ve desafiado por la espacialidad del lirismo, pero este mismo contribuye a la trama no sólo en calidad de retardante o "motivo no funcional" (Tomashevski, 1970), sino más bien como enlace efectivo de la heterogeneidad. Es por ello que la narrativa de Bolaño revela su autenticidad precisamente en la medida en que se hace cargo de la conflictividad del mundo, las formas de la trama o del tiempo empleados en sus relatos son más que una resignación ante el desconsuelo, sin necesidad de optar por un optimismo ingenuo.

\section{Conclusión}

Las aserciones desarrolladas aquí se hallan condicionadas por los cuentos que manifiestan una trama problemática y, por tanto, no pueden menos que adquirir grados de corrección respecto a la vasta producción narrativa de Bolaño. Además, una investigación del tiempo y la trama en Bolaño habrá de completarse con el examen de su producción novelesca, tanto más cuanto que allí las estrategias mencionadas cobran una nueva magnitud, baste pensar en el problema de la unidad en 2666. De igual forma es necesario un análisis más profundo del cronotopo que rige la poética de Bolaño, sobre todo considerando que las acciones episódicas derivan en la reversibilidad y su relación con la espacialidad podría dar la clave de una suerte de orden.

Si bien no pretendemos agotar el tema de la trama, se ha podido observar que la peculiaridad estética de los cuentos de Bolaño guarda relación con las estrategias que utiliza a modo de sustitutos de los enlaces narrativos de una trama tradicional. A través de estos procedimientos auxiliares la ficción cambia sin necesidad de abandonar lo que es. Pero sobre todo, estas formas narrativas son la clave de la perspectiva y el valor simbólico de la propuesta literaria en tanto respuesta a problemas que son a la vez estéticos y sociales. Desde luego, se ha de admitir la caracterización que hace Rojo (2016) del ciclo literario al que pertenece Bolaño por cuanto

${ }^{10}$ Según la etimología relativa a éschatos. 
delimita el contexto histórico y social que lo condiciona y lo torna comprensible. Pero la manera en que esta condición adquiere una dimensión estética se encuentra en las formas propiamente narrativas utilizadas por el autor, particularmente la configuración del tiempo y la trama. En este sentido, podemos observar que el así llamado pesimismo de los cuentos de Bolaño se ve al menos compensado con una imagen abierta del acontecimiento humano; más importante aún, la mutua implicación de los destinos de personajes y mundo sugiere que esta apertura es accesible a la acción humana, bien que no se encuentra garantizado ningún éxito humanista basado en alguna certeza ideológica o metafísica.

\section{Referencias}

Aguilar, P. (2015). Fantasma, memoria y poesía desde "Últimos atardeceres en la tierra" de Roberto Bolaño. En P. Aguilar, y T. Basite, (Ed.), Bolaño en sus cuentos (pp. 125-135). Leiden: Alemenara.

Andrews, C. (2003) 'Algo va a pasar': los cuentos de Roberto Bolaño. En F. Moreno (Coord.) Roberto Bolaño: una literatura infinita (pp. 33-40). Poitiers: Université de Poitiers.

(2008). La experiencia episódica y la narrativa de Roberto Bolaño. En E. Paz Soldán, y G. Faverón. (Comps.). Bolaño Salvaje (pp. 53-72). Barcelona: Candaya.

(2015). Epifanías e inminencia en los cuentos de Roberto Bolaño. En P. Aguilar, y T. Basile (Ed.). Bolaño en sus cuentos (pp. 27-42). Leiden, Países Bajos: Almenara.

Aristóteles (2013). Poética. México D.F.: Porrúa.

Ayala, M. (2008). Notas sobre la poesía de Roberto Bolaño. En E. Paz Soldán, y G. Faverón. (Comps.). Bolaño Salvaje (pp. 09-10). Barcelona: Candaya.

Bajtín, M. (1989). Teoría y estética de la novela. Madrid: Taurus.

Bal, M. (1990). Teoría de la narrativa. Madrid: Cátedra.

Benjamin, W. (2007). Conceptos de filosofía de la historia. Buenos Aires: Terramar.

Bremond, C. (1972). La lógica de los posibles narrativos. En Barthes et al. (Ed.), Análisis estructural del relato (pp. 87-109). Buenos Aires: Tiempo contemporáneo.

(1974). El mensaje narrativo. En R. Barthes, et al. (Ed.), La semiología, (pp. 75104). Buenos Aires: Tiempo contemporáneo.

Bolaño, R. (2001). Putas asesinas. Barcelona: Anagrama. (2004). Entre paréntesis. Barcelona: Anagrama. (2009). El gaucho insufrible. Barcelona: Anagrama. (2018). Cuentos completos. Santiago: Alfaguara.

Borges, J.L. (1999). Prólogo. En Bioy Casares, A. La invención de Morel. Buenos Aires: Emecé. Corral, W. (2011). Bolaño traducido. Nueva literatura mundial. Madrid: Escalera.

Eco, U. (1992). Obra abierta. Barcelona: Planeta-De Agostini.

Hegel, G.W. F. (2011). Lecciones sobre la estética. Madrid: Akal.

Jameson, F. (1989). Documentos de cultura, documentos de barbarie. Madrid: Visor. (2013). Valencias de la dialéctica. Buenos Aires: Eterna Cadencia.

Kermode, F. (2000), El sentido de un final. Barcelona: Gedisa.

Lotman, Y. (2011). Estructura del texto artístico. Madrid: Akal.

Lukács, G. (1966 b). Narrar o describir. A propósito de la discusión sobre naturalismo y formalismo. En C. Gerhard (Trad.), Problemas del realismo, (pp. 171-216). México D.F.: Fondo de cultura económica.

Moretti, F. (2015). Lectura distante. Buenos Aires: Fondo de cultura económica.

Piglia, R. (2017). Formas breves. Buenos Aires: Debolsillo. 
Rancière, J. (2009). La palabra muda. Ensayo sobre las contradicciones de la literatura. Buenos Aires: Eterna cadencia.

(2011). Política de la literatura. Buenos Aires: Libros del Zorzal.

Ricoeur, P. (2017). Tiempo y narración II. Configuración del tiempo en el relato de ficción. México: Siglo XXI.

(1997). Narratividad, fenomenología y hermenéutica. En G. Aranzueque (Trad.), Cuaderno Gris. Época III, (2). https://repositorio.uam.es/handle/10486/225

Rojo, G. (2016). Las novelas de la dictadura y posdictadura chilena. ¿Qué y cómo leer? Santiago: Lom.

Ríos, F. (2015). Fuera de aquí: la literatura más allá de lo literario en la cuentística de Bolaño. En P. Aguilar, y T. Basile (Eds.), Bolaño en sus cuentos (pp. 13-26). Leiden: Almenara

Solotorevsky, M. (2009). El "espesor escritural" en dos cuentos de Roberto Bolaño: "Últimos atardeceres en la tierra" y "Dentista". Revista laboratorio. Literatura y experimentación, 2, 1-12. https://revistalaboratorio.udp.cl/index.php/laboratorio/article/view/100/94

Tinianov, J. (1970). Sobre la evolución literaria. En T. Todorov (Comp.) Teoría de la literatura de los formalistas rusos (pp. 89-101). Buenos Aires: Signos.

Todorov, T. (2012). Los géneros del discurso. Buenos Aires: Waldhuter.

Tomashevski, B. (1970). Temática. En T. Todorov (Comp.) Teoría de la literatura de los formalistas rusos (pp. 199-232). Buenos Aires: Signos. 